\title{
ECONOMICALLY OPTIMUM STRUCTURAL DESIGN: METHODOLOGY AND CASE STUDY
}

\author{
MILAN HOLICKY ${ }^{1}$, DIMITRIS DIAMANTIDIS ${ }^{2} \&$ MIROSLAV SYKORA $^{1^{*}}$ \\ ${ }^{1}$ Klokner Institute, Czech Technical University in Prague, Czech Republic \\ ${ }^{2}$ Faculty of Civil Engineering, Ostbayerische Technische Hochschule Regensburg, Germany
}

\begin{abstract}
Codes of practice aim to assure structures have acceptable risks to the public and the minimum total costs over the working life of a design. However, current codified criteria for structural design correspond to a broad range of reliability levels, specified for dissimilar reference periods even though their recalculation for different periods is uncertain due to unknown dependence of failure events in time. In this contribution, target reliability levels are specified on the basis of probabilistic risk optimization considering the objective function as a sum of various costs including effects of time to failure and discounting. A case study presents probabilistic optimization of the roof of a stadium for 4,000 spectators and illustrates the effect of the considered input parameters. Failure consequences and relative cost of safety measure are shown to be major factors affecting the optimum reliability level. Less important factors are the discount rate and working life. Large uncertainty in failure cost estimates seems to have only a marginal effect on derived optimum reliability levels.
\end{abstract}

Keywords: failure consequences, probabilistic optimization, risk acceptance, stadium, target reliability, total cost, working life.

\section{INTRODUCTION}

Codes of practice aim at assuring structures having the risks acceptable to the public and the minimum total costs over a design working life. To ensure applicability, design procedures are based on numerous compromises. The link with the theoretical background may then be masked or lost. This is the case of the target reliability levels in various national and international documents for new structures. They are inconsistent in terms of the recommended values and the criteria according to which the appropriate values are to be selected. EN 1990 [1] recommends reliability indices for two reference periods, 1 year and 50 years (Table 1), without any explicit link to the design working life that may differ from the reference period. No specific values are given for temporary or long-term structures.

It should be emphasized that the reference period is understood as a chosen period of time used as a basis for statistical assessment of the time variant basic random variables, and the corresponding probability of failure. The reference period may be therefore different from the design working life. Confusion is often caused when the difference between these two concepts is missed.

The couples of annual and 50-year $\beta$ values in Table 1 for each RC corresponds to the same reliability level provided that time-variant variables (e.g. imposed and climatic loads) dominate reliability of the structure. Practical application of the concept of reference period depends on the time period considered in the verification, which may be linked to available probabilistic information concerning time variant basic variables (imposed load, wind, earthquake, etc.); see [2]. A 50-year reference period is commonly adopted as a design working life for ordinary structures [3].

*ORCID: http://orcid.org/0000-0001-9346-3204 
Table 1: Reliability classification in accordance with EN 1990 [1].

\begin{tabular}{|l|c|c|c|l|}
\hline \multirow{2}{*}{$\begin{array}{l}\text { Reliability } \\
\text { classes }\end{array}$} & \multirow{2}{*}{$\begin{array}{c}\text { Failure } \\
\text { consequences }\end{array}$} & \multicolumn{2}{|c|}{$\begin{array}{c}\text { Reliability index } \beta \text { for } \\
\text { reference period }\end{array}$} & \multirow{2}{*}{$\begin{array}{l}\text { Examples of buildings and } \\
\text { civil engineering works }\end{array}$} \\
\cline { 3 - 4 } & & 1 year & 50 years & \\
\hline RC3 - high & High & 5.2 & 4.3 & Bridges, public buildings \\
\hline RC2 - normal & Medium & 4.7 & 3.8 & Residences and offices \\
\hline RC1 - low & Low & 4.2 & 3.3 & Agricultural buildings \\
\hline
\end{tabular}

Following Rackwitz [4], the JCSS Probabilistic Model Code [5] provides a more detailed recommendation. Annual target reliability levels are associated with failure consequences as well as with the relative costs of safety measures; see Table 2 . The JCSS consequence classes - similar to EN 1990 [1] - are defined on the basis of the ratio $\rho=\left(C_{\text {str }}+C_{\mathrm{f}}\right) / C_{\text {str }}$ where $C_{\text {str }}$ is the construction, and $C_{\mathrm{f}}$ is the direct failure cost.

Costs of failure including human losses are subjected to considerable scatter and cannot be easily assessed by designers. For instance they depend on various non-structural aspects such as rescue measures. Therefore, it appears appealing in codified design to recommend a safety class differentiation for exposure levels [3]. In this contribution the failure costs $C_{\mathrm{f}}$ cover all additional direct and indirect human, economic and environmental losses caused by the failure; see Diamantidis et al. [6] for further discussion while the structural cost is considered separately.

\section{BASIS OF COST OPTIMIZATION}

The following objective function presents the total expected cost $C_{\text {tot }}(x, q, n)[2]$ :

$$
C_{\mathrm{tot}}(x, q, n)=C_{\mathrm{str}} \sum_{i} P_{\mathrm{f}}(x, i) /(1+q)^{i}+C_{\mathrm{f}} \sum_{i} P_{\mathrm{f}}(x, i) /(1+q)^{i}+C_{0}+x C_{1},
$$

where $x=$ decision parameter to be optimised the optimization (commonly a structural resistance parameter), $q=$ annual discount rate, $n=$ number of years to structural failure, $P_{\mathrm{f}}(x, i)=$ probability of failure in year $I, C_{0}=$ initial cost independent of $x$, and $C_{1}=$ unit cost of $x$.

Failure events can be assumed to be independent in subsequent years when failure probabilities are governed by time-variant actions (imposed, traffic and/ or climatic loads, accidental actions). Annual failure probability $P_{\mathrm{f}}(x, i)$ in year $i$ can be reasonably approximated by the geometric sequence:

$$
P_{\mathrm{f}}(x, i) \approx p(x)[1--p(x)]^{i-1} .
$$

It can be shown that eqn (2) provides good estimates even for relatively high dependency between annual failure events; this dependency can be caused by time-invariant parameters of resistances and loads, or by a long-term nature of some time-variant loads such as sustained

Table 2: Tentative target reliability indices $\beta$ related to one year reference period and ultimate limit states in accordance with the JCSS PMC [5].

\begin{tabular}{|l|c|c|c|}
\hline \multirow{2}{*}{ Relative costs of safety measures } & \multicolumn{3}{|c|}{ Consequences of failure } \\
\cline { 2 - 4 } & Minor & Moderate & Large \\
\hline Large & 3.1 & 3.3 & 3.7 \\
\hline Normal & 3.7 & 4.2 & 4.4 \\
\hline Small & 4.2 & 4.4 & 4.7 \\
\hline
\end{tabular}


component of imposed loads [5]. Obviously initial annual failure probability $p(x)$ depends on $x$. Assuming the independency of annual failure events, probability of failure $P_{\mathrm{fn}}(x)$ during $n$ years is obtained as the sum of $P_{\mathrm{f}}(x, i)$ for $i=1 . . n$ :

$$
P_{\mathrm{fn}}(x, n)=1-[1-p(x)]^{n} \approx n p(x) .
$$

This approximation provides good estimates for $p(x)<10^{-3}$ that are typical for ultimate limit state verifications.

Considering eqns (1) and (2), the total costs $C_{\text {tot }}(x, q, n)$ described by eqn (1) may be written in a simplified form as:

$$
C_{\text {tot }}(x, q, n)=\left(C_{\text {str }}+C_{\mathrm{f}}\right) p(x) P Q(x, q, n)+C_{0}+x C_{1} .
$$

Here the total sum of expected malfunction costs during the period of $n$ years is dependent on the product of the present value of malfunction $\operatorname{cost} C_{\mathrm{f}}$, the annual probability $p(x)$ and a sum of the geometric sequence having the quotient $(1-p(x)) /(1+q)$, denoted as the time factor $P Q(x, q, n)$ :

$$
P Q(x, q, n)=\frac{1-\left[\frac{1-p(x)}{1+q}\right]^{n}}{1-\left[\frac{1-p(x)}{1+q}\right]}
$$

In general, the total cost $C_{\text {tot }}(x, q, n)$ depends on the costs $C_{0}, C_{1}, C_{\mathrm{f}}$, failure probability $p(x)$, discount rate $q$, and working life $n$.

The necessary condition for the minimum of the total cost follows from (1) as:

$$
\frac{\delta C_{t o t}(x, q, n)}{\delta x}=\rho\left[\frac{\delta}{\delta x}(p(x) P Q(x, q, n))\right]_{x=x_{o p t}}+\frac{C_{1}}{C_{s t r}}=0 .
$$

Eqn (6) represents a general form of the necessary condition for the minimum of total cost $C_{\text {tot }}(x, q, n)$, the optimum value $x_{\mathrm{opt}}$ of the parameter $x$, and the optimum annual probability of failure $p_{\text {opt }}=p\left(x_{\mathrm{opt}}\right)$. The optimum probability and reliability index for the design working life are obtained as follows:

$$
P_{\text {fn,opt }}=1-\left(1-p_{\text {opt }}\right)^{n} \approx n p_{\text {opt }} ; \beta_{\text {opt }}=-\Phi^{-1}\left(P_{\text {fn,opt }}\right) .
$$

\section{OPTIMUM RELIABILITY LEVELS: REPRESENTATIVE VALUES}

To provide representative target reliability indices, a generic structural member is described by the limit state function $Z(x)$ as:

$$
Z(x)=x f-(G+Q) .
$$

Here $x$ denotes a deterministic structural parameter (e.g. the cross-section area), $f$ the strength of the material, $G$ the load effect due to permanent load and $Q$ the load effect due to variable load. The representative theoretical models of the random variables $f, G$ and annual maxima of $Q$ are adopted from [5], [7]:

- $f$ - lognormal (unity mean/ coefficient of variation of $10 \%$ );

- $G-\operatorname{normal}(0.35 / 10 \%)$;

- $Q$ - Gumbel $(0.1 / 50 \%)$. 
The annual failure probability $p(x)$ is obtained as $\mathrm{P}[Z(x)<0]$. For $x=1$ and $n=50$, failure probability is $P_{\mathrm{fn}}(1.50)=6.7 \times 10^{-5}$ and corresponding reliability index $\beta \approx 3.8$.

The total costs $C_{\text {tot }}(x, q, n)$ given by eqn (4) are transformed to the standardized form $\kappa_{\text {tot }}(x, q, n)$ given as:

$$
\kappa_{t o t}(x, q, n)=\frac{C_{t o t}(x, q, n)-C_{0}}{C_{1}}=x+\rho \frac{C_{s t r}}{C_{1}} p(x) P Q(x, q, n),
$$

where $\rho=\left(C_{\text {str }}+C_{\mathrm{f}}\right) / C_{\text {str }}$.

Assuming $q=0.03$ and $n=50$ years, Fig. 1 shows the variation of the total standardized costs $\kappa_{\text {tot }}(x, q, n)$ and the optimum reliability index $\beta_{\text {opt }}$ with the structural parameter $x$. The optimal values $x_{\mathrm{opt}}(q, n)$ of the structural parameter $x$, given by eqn (6), are shown by the dotted vertical lines. In the case of independent annual failure probabilities, the indicated values $(\beta=2.6,3.2$, and 3.5) correspond to annual rates 3.7, 4.2, and 4.4, respectively, recommended by the JCSS PMC [5] (Table 2) for "normal relative costs of safety measures".

Note that the cost ratio $\rho=1$ corresponds to the extreme situation when costs of failure $C_{\mathrm{f}}$ are negligible. For $\rho=1$ and $C_{\text {str }} / C_{1}=100$, it follows from Fig. 1 that the optimum design parameter $x_{\text {opt }}$ is about 0.9 and the optimum reliability index $\beta_{\text {opt }} \approx 3.3$. When $\rho$ increases to 100 , then $x_{\text {opt }} \approx 1.02$ and $\beta_{\text {opt }} \approx 4.4$.

Fig. 2 displays $\beta_{\text {opt }}$ as a function of $\rho$ for $n=50, q=0.03$, and $C_{\text {str }} / C_{1}=10,100$, and 1,000. The optimum reliability obviously depends on $C_{\text {str }} / C_{1}$ as well as on $\rho$. The optimum reliability index ranges from 2.5 up to 4.5 for $C_{\text {str }} / C_{1}=10-1000$ and $\rho=1-10$ - the range for minor to large failure consequences in the JCSS PMC [5].

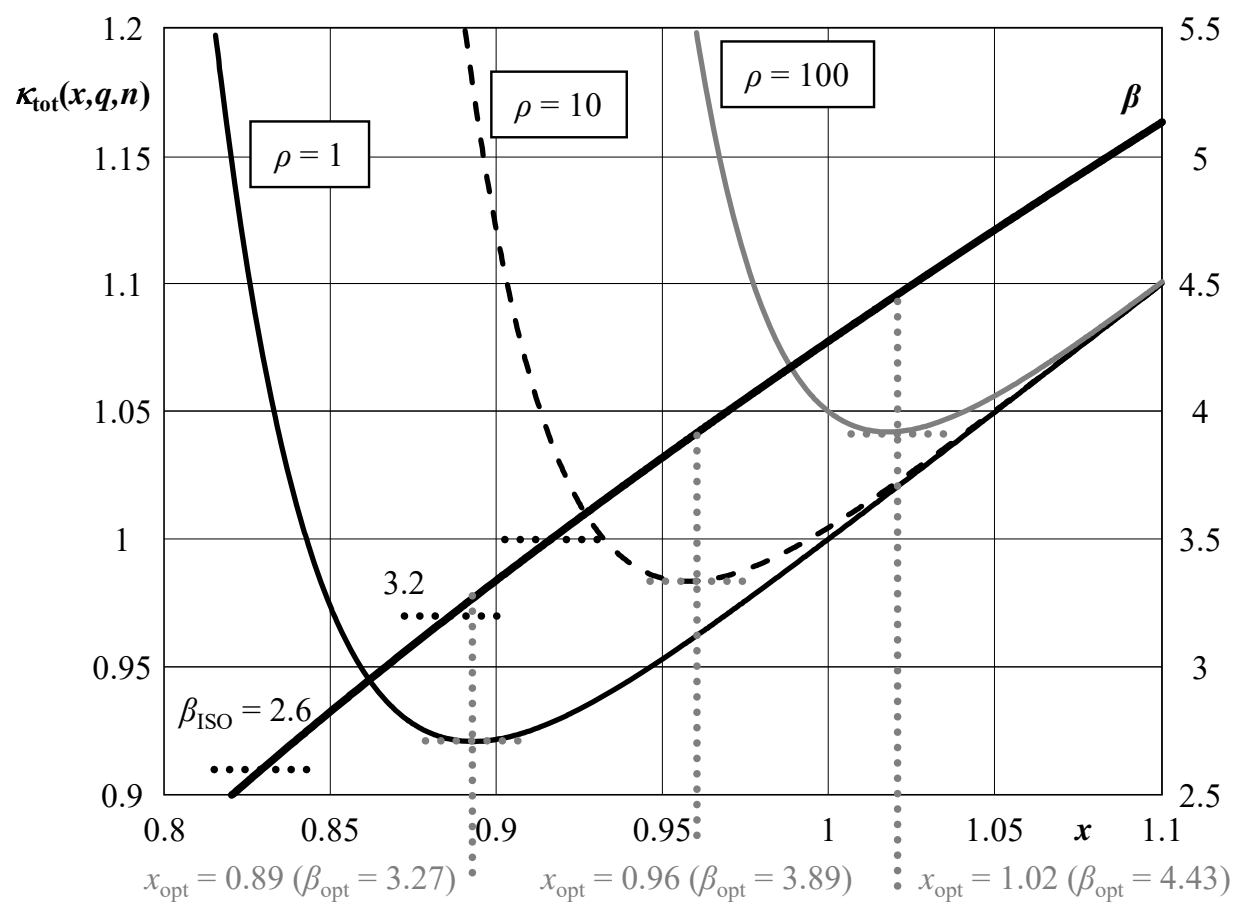

Figure 1: Variation of total standardized $\operatorname{cost} \kappa_{\mathrm{tot}}(x, q, n)$ and reliability index $\beta$ with decision parameter $x$ for $q=0.03, n=50, C_{\text {str }} / C_{1}=100$, and selected ratios $\rho$. 


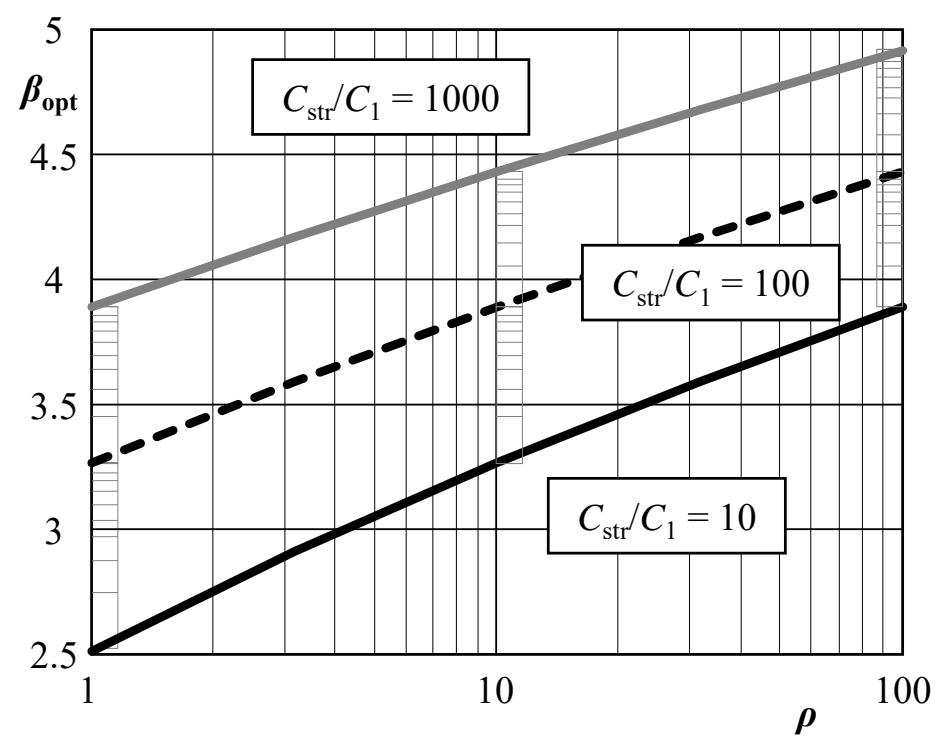

Figure 2: $\quad \beta_{\mathrm{opt}}\left(q, n, C_{\mathrm{str}} / C_{1}, \rho\right)$ as a function of $\rho\left(n=50 ; q=0.03\right.$; and various ratios $\left.C_{\mathrm{str}} / C_{1}\right)$.

Note the annual discount rate should be a long-term average, net of inflation and taxes [8]; for European economies it is often approximated by $q=3 \%$. Lower values lower were proposed in [9], [10] for sustainable intergenerational decision making associated with longer lifetimes. Holicky [11] and Diamantidis et al. [6] showed that the decrease of $1-2 \%$ commonly has a small effect on the target levels. The additional analysis indicates that the optimum reliability index $\beta_{\text {opt }}$ is insignificantly influenced by time $n\left(\beta_{\text {opt }}\right.$ slightly decreasing with increasing $q$ and $n$ ). A conservative approximation of the optimum reliability index is obtained for reduced $n(\approx 10)$ and low $q$ (for instance 0.01$)$.

\section{CASE STUDY: OPTIMUM RELIABILITY OF THE ROOF OF A STADIUM}

\subsection{Basic information}

The case study is focused on the design of the roof of a stadium. The open-roof stadium can accommodate up to 4000 people and it is used to host sport events, concerts and shows. Snow load is dominating structural reliability of the roof that consists of 40 identical cantilever steel beams (Fig. 3), spaced each $5 \mathrm{~m}$. The IPE450 profile complies with the reliability condition for bending moments using the partial factor method in EN 1990 [1].

The reliability of a cantilever was analysed by the authors [12] by applying the limit state function according to eqn (8):

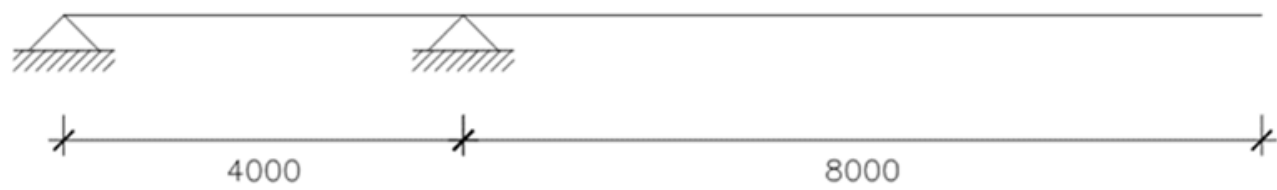

Figure 3: Scheme of the cantilever (in $\mathrm{mm}$ ). 
- $\quad x=W_{\mathrm{pl}} / W_{\mathrm{pl}(\mathrm{IPE} 450)}-$ plastic section modulus, relatively to $W_{\mathrm{pl}}$ of IPE450;

- $f$-yield strength of steel including model uncertainty in the resistance model;

- $Q$ - roof snow load.

The random variables were described by probabilistic models similar to those adopted in Section 3. The models for $G$ and $Q$ included also uncertainty in the load effect model.

In comparison to the generic structural member in Section 3:

1. The reliability of the roof cantilevers is more dominated by $Q$ while the contribution of $G$ is less significant.

2. Annual maxima of the roof snow load are associated with a larger coefficient of variation of $60 \%$ (50\% assumed in Section 3).

This is why uncertainty in the total load effect is slightly larger for the cantilever than for the generic beam. Rackwitz [4] showed that such increase in uncertainty somewhat reduces the optimum target reliability indices $\beta_{\text {opt. }}$. Consequently, it is slightly conservative to estimate $\beta_{\text {opt }}$ for the cantilever using Fig. 2, but it can be shown that this simplification is entirely acceptable from a practical point of view. Note that the cantilever fulfils the assumption of independent failure events. Note that serviceability aspects are not discussed hereafter.

\subsection{Structural and failure costs}

Assuming $q=0.03$ and $n=50$ years, the ratios $\rho$ and $C_{\text {str }} / C_{1}$ need to be determined to specify $\beta_{\text {opt }}$. All the cost estimates relate to the roof structure. Fig. 4 displays $\operatorname{cost} C_{1}(x)$ per unit of a decision parameter in thousands of $€(\mathrm{k} €)$. $C_{1}(x)$ is estimated considering the cost of steel profiles for the 40 cantilevers, each spanning $12 \mathrm{~m}$. It appears that the relationship between $C_{1}$ and $x$ is somewhat non-linear, but it is acceptable to use a linear approximation

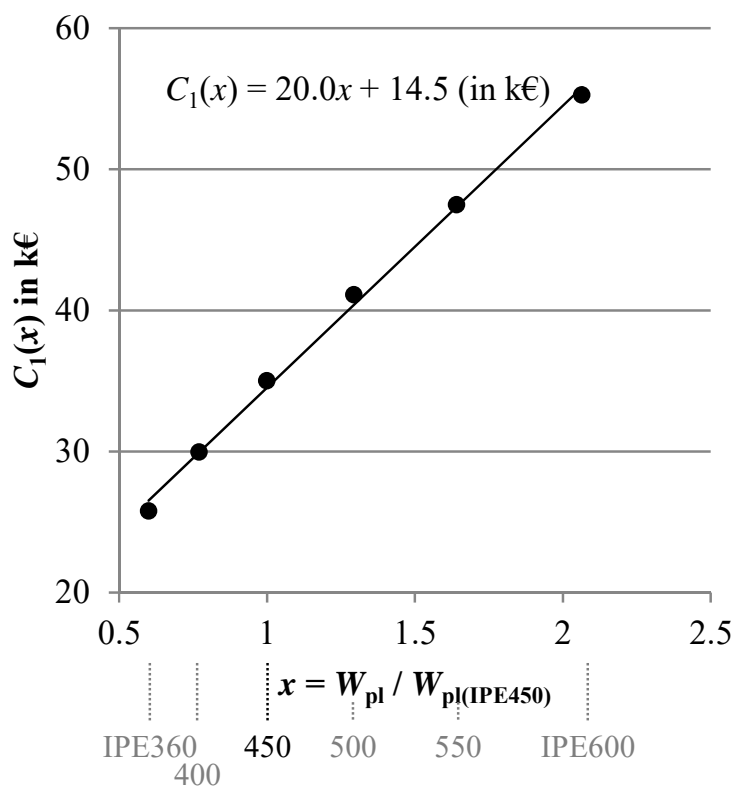

Figure 4: $\operatorname{Cost} \mathrm{C} 1(\mathrm{x})$ per unit of a decision parameter in $\mathrm{k} €$. 
around $x=1$ (thus close to an expected optimum solution). With reference to eqn (1) and Fig. $4, C_{1}=20 \mathrm{k} €$ is further considered.

The construction cost of the whole roof is estimated as $1000 \mathrm{k} €$, considering labour, material, and paint costs of main and secondary structural members and of roofing. Following the indications provided in [13], [14], damage of $10-25 \%$ roof area with subsequent replacement of the whole structure is assumed, $C_{\mathrm{str}} / C_{1}=50$. This is close to the lowest ratio considered in Section 3. In general a low $C_{\text {str }} / C_{1}$ ratio is expected for the structures with dominating costs of load bearing system such as bridges or roofs. The ratio increases for office and residential buildings where costs of design, execution, and of secondary structural members are significant.

Failure costs $C_{\mathrm{f}}$ include demolition cost, economic losses due to non-availability of the stadium and societal consequences - costs of injuries and fatalities. Demolition and clean-up cost is estimated as $25 \%$ of $C_{\text {str }}, 250 \mathrm{k} €$. Economic consequences consist of business losses due to closure of the stadium:

- Time required to overcome the damage is estimated to be six months considering the statistical information provided in [15].

- The economic loss resulting from cancelled or postponed events and travel and rent cost of a home team, sharing temporarily a nearby stadium, range from $200 \mathrm{k} €$ to $400 \mathrm{k} €$.

Human losses are expected to significantly contribute to the total failure consequences:

- Event 1 - stadium is occupied $\left(E_{1}\right)$. In a winter season, the occupancy is on average 2000 spectators and 200 to 500 persons are thus expected to be under the collapsed area. Eldukair \& Ayyub [15] and Sykora et al. [16] indicated that conditional probability of casualty given the structural failure could be in the order of magnitude of $1 \%$. The former reference considered also stadia; for further information see [17], [18]. Considering the range from $1 \%$ to $5 \%$, the expected number of fatalities becomes:

$$
N_{\mathrm{f} \mid E 1} \approx<200,500>\times<0.01,0.05>=<2,25>\text { fatalities. }
$$

The important assumption is that the utilisation of the stands by spectators has negligible effect on the likelihood of the roof collapse as the corresponding load due to the crowd of people does not increase loading of the roof system.

- Event $2\left(E_{2}\right)$ - in other time periods, the stadium is occupied only by technical staff, coaches, and rarely by sportsmen and spectators. It is expected that 1 to 30 persons can be endangered and then the expected number of fatalities is:

$$
N_{\mathrm{f} \mid E 2} \approx<1,30>\times<0.01,0.05>=<0.01,1.5>\text { fatalities. }
$$

- For the duration of the event $E_{1}$ of around three hours per two weeks in a winter season, Event 1 occurs with probability $\mathrm{P}\left(E_{1}\right)=3 / 336=9 \%$ and the expected number of fatalities given the partial collapse of the roof becomes:

$$
N_{\mathrm{f}} \approx<2,25>\times 0.009+<0.01,1.5>\times(1-0.009)=<0.03,1.7>\text { fatalities }
$$

Therefore, up to two fatalities are expected. This number is low in comparison to the maximum number of persons at risk and also might seem to be in contradiction with the study by Trbojevic [19] who assumed 10-100 fatalities for structures with large risk of injury or casualty. However, two important aspects of the present case study justify the low $N_{\mathrm{f}}$ : 
3. The collapse is expected in a winter season when the stadium is rarely used.

4. The independency of a failure mode and imposed load is assumed.

The second aspect makes failure consequences distinctly different from e.g. bridges or dancing halls where failure is more likely at times when the structure is fully occupied.

- The human losses can be transformed into monetary units by multiplying $N_{\mathrm{f}}$ by the Societal Value of Statistical Life (SVSL $\approx 2000 \mathrm{k} €$ considered here) according to the Life Quality Index approach provided in ISO 2394 [20]. Considering that the losses due to injuries are typically in the same order of the magnitude as those for casualties [6], the total human losses are $C_{\text {human }} \approx<0.03,1.7>\times 2 \times 2000 \mathrm{k} €=120-6800 \mathrm{k} €$.

The failure consequences are expressed as the sum of the economic and human losses:

$$
C_{\mathrm{f}}=250+<200,400>+<120,6800>=<570, \sim 7500>\mathrm{k} €,
$$

which leads to $\rho=<1.6,8.5>$ and demonstrates the large scatter of the consequence estimate.

Considering $C_{\text {str }} / C_{1}=50$ and $\rho=2-9, \beta_{\text {opt }}(n=50$ y.) $\approx 3.3-3.7$ is obtained from Fig. 2 and the corresponding $\beta_{\text {opt }}(n=1 \mathrm{y})=.4.3-4.6$ is determined using eqn (7). The range of annual values complies well with:

- The annual optimum target reliability provided in ISO 2394, Table G.4 where $\beta_{\text {opt }}(n=$ $1 \mathrm{y}.)=4.4$ is indicated for high failure consequences (Class 4 in the ISO standard) and medium relative cost of safety measure

- The minimum requirement on human safety $\beta_{\min }(n=1 \mathrm{y})=$.3.7 as indicated in ISO 2394 , Table G.3 for medium relative cost of safety measures

- The annual acceptable reliability index $\beta_{\min }(n=1 \mathrm{y})=$.4.4 given in ASCE 7-10 [21], Table C.1.3.1a for Occupancy Category IV ( $>2500$ lives at risk) and failure that is not sudden and does not lead to wide-spread progression of damage

EN 1990 gives annual $\beta$ of 5.2 for high failure consequences. The lower optimum level is attributable to the fact that the hazard situation - the roof under heavy snow is expected to occur in a winter season when the open-roof stadium is rarely occupied.

An important assumption is that $10-25 \%$ of the roof area will be affected by the collapse. For some types of roofs (mostly for fully covered spaces), full collapses have been observed. Assuming the full collapse of the stadium under consideration, economic losses could be similar as for the partial collapse while the human losses could be magnified by a factor of four. With reference to eqn (13), this would lead to upper bounds of the failure consequences and $\rho$-ratio:

$$
C_{\mathrm{f}} \leq 450+27200 \approx 28000 \mathrm{k} €(\rho=29)
$$

For $C_{\text {str }} / C_{1}=50$ and $\rho=30, \beta_{\text {opt }}(n=50 \mathrm{y}$. $) \approx 4.0$ is obtained from Fig. 2 and the corresponding annual target is $\beta_{\text {opt }}(n=1 \mathrm{y})=$.4.8 . It appears that the optimum target level is not affected significantly by uncertainty in the failure cost estimate.

\section{DISCUSSION}

\subsection{Lifetime vs annual target levels}

The methodology of economic optimisation presented in Section 2 is based on minimising total cost related to a working life of the structure. Similar approaches were adopted in numerous previous studies [22]-[26]. By contrast, Rackwitz [4] assumed that the structure is 
replaced by the same structure after failure. Considering the asymptotic behaviour in an infinite time horizon, he obtained annual optimum target levels that have been later adapted in the JCSS PMC [5] and ISO 2394 [20]. In a long-term perspective of decades and hundreds of years, the assumption of periodical replacement may be reasonable for some residential and office buildings, some bridges or some tunnels while it may be unrealistic in other situations, e.g. for the structures:

- Serving specific ever-developing purposes of industry - a rapidly changing power sector provides a good example nowadays.

- Exposed to increasing traffic loads.

- Re-assessed in the light of sustainability and life-cycle considerations.

\subsection{Existing structures}

At present, existing structures are mostly verified using conservative procedures based on the partial factor method for structural design. A more realistic verification can be achieved by probabilistic methods. Specification of the target reliability levels is needed for these assessments, as well as modifications of partial factors [18], [27], [28].

For existing structures it may be uneconomical to require the same reliability levels as for new structures [16], [29]-[31]. The target level for existing structures usually decreases as it takes relatively more effort to increase the reliability level then for a new structure. Two reliability levels are needed in the assessment of existing structures - the minimum level below which the structure is unreliable and should be upgraded, and the target level indicating an optimum upgrade strategy [18]. Available experience indicates that the minimum level is often dominated by the human safety criteria whilst the optimum repair level is close to the target level accepted for structural design.

When an existing structure fails to meet reliability criteria, monitoring can be used to provide early warning and ensure adequate reliability [12], [32]. The principles of assessment of existing structures were recently established in the CEN Technical Specifications [33], providing the basis for rules to be included in Eurocodes.

\section{CONCLUSIONS}

The submitted study indicates that the target reliability can be derived on the basis of probabilistic optimization, considering failure and structural costs. The latter is discounted over a reference period, i.e. working life of the structure. The following conclusions are drawn from the presented numerical examples:

- Costs of improving structural safety and failure consequences are main factors affecting the optimum reliability index $\beta_{\text {opt }}$. A conservative estimate of $\beta_{\text {opt }}$ is obtained when a low discount rate and short working life are taken into account.

- It appears that the optimum target level is not affected significantly by uncertainty in the failure cost estimate.

For practical applications, a clear guideline for consequence class differentiation is needed; otherwise such procedures will remain being used in theoretical studies and will not find attention of the industry.

\section{ACKNOWLEDGEMENTS}

This work was supported by the Czech Science Foundation under Grant 16-11378S, by the Ministry of Education, Youth and Sports of the Czech Republic under Grant LTT18003, by 
the Regensburg Centre of Energy and Resources (RCER) of OTH Regensburg and by the Technology and Science Network Oberpfalz (TWO). Outcomes of COST Action TU1402 have been utilized.

\section{REFERENCES}

[1] EN 1990, Eurocode - Basis of Structural Design, CEN: Brussels, 87 pp., 2002.

[2] Holicky, M., Optimum reliability levels for structures. Vulnerability, Uncertainty, and Risk, American Society of Civil Engineers, pp. 184-193, 2014.

[3] Holicky, M. et al., Load Effects on Buildings (Guidebook 1), CTU in Prague: Prague, 214 pp., 2009.

[4] Rackwitz, R., Optimization - The basis of code-making and reliability verification. Structural Safety, 22(1), pp. 27-60, 2000. DOI: http://dx.doi.org/10.1016/S01674730(99)00037-5.

[5] JCSS, JCSS Probabilistic Model Code (periodically updated, online publication), Joint Committee on Structural Safety, 2018.

[6] Diamantidis, D., Holicky, M. \& Sykora, M., Target reliability levels based on societal, economic and environmental consequences of structural failure. Proceedings of ICOSSAR 2017, TU-MV Media Verlag GmbH: Vienna, pp. 644-653, 2017.

[7] Sykora, M., Holicky, M., Markova, J. \& Senberger, T., Probabilistic Reliability Assessment of Existing Structures (Focused on Industrial Heritage Buildings), Czech Technical University in Prague, CTU Publishing House: Prague, 108 pp., 2016.

[8] Rackwitz, R., Lentz, A. \& Faber, M., Socio-economically sustainable civil engineering infrastructures by optimization. Structural Safety, 27(3), pp. 187-229, 2005. DOI: 10.1016/j.strusafe.2004.10.002.

[9] Lee, J.Y. \& Ellingwood, B.R., Ethical discounting for civil infrastructure decisions extending over multiple generations. Structural Safety, 57, pp. 43-52, 2015. DOI: http://dx.doi.org/10.1016/j.strusafe.2015.06.001.

[10] Nishijima, K., Straub, D. \& Faber, M.H., Inter-Generational Distribution of the LifeCycle Cost of an Engineering Facility, pp. 33-46, 2007.

[11] Holicky, M., Optimisation of the target reliability for temporary structures. Civil Engineering and Environmental Systems, 30(2), pp. 87-96, 2013. DOI: 10.1080/ 10286608.2012.733373.

[12] Diamantidis, D., Sykora, M. \& Lenzi, D., Optimizing monitoring: standards, reliability basis and application to assessment of roof snow load risks. Structural Engineering International - Journal of IABSE, 2018 (in press).

[13] Holicky, M. \& Sykora, M., Failures of roofs under snow load: Causes and reliability analysis. Forensic Engineering, Proceedings of the Congress, pp. 444-453, 2010.

[14] Geis, J., Strobel, K. \& Liel, A., Snow-induced building failures. Journal of Performance of Constructed Facilities, 26(4), pp. 377-388, 2012. DOI: 10.1061/ (ASCE)CF.1943-5509.0000222.

[15] Eldukair, Z.A. \& Ayyub, B.M., Analysis of recent U.S. structural and construction failures. Journal of Performance of Constructed Facilities, 5(1), pp. 57-73, 1991.

[16] Sykora, M., Holicky, M., Jung, K. \& Diamantidis, D., Target reliability for existing structures considering economic and societal aspects. Structure and Infrastructure Engineering, 13(1), pp. 181-194, 2016. DOI: 10.1080/15732479.2016.1198394.

[17] Lentz, A., Acceptability of civil engineering decisions involving human consequences. PhD thesis, TU Munich, Munich, 165 pp., 2007.

[18] fib COM3 TG3.1, Partial Factor Methods for Existing Structures (fib Bulletin 80, recommendation), fib, pp. 129, 2016. 
[19] Trbojevic, V.M., Another look at risk and structural reliability criteria. Structural Safety, 31(3), pp. 245-250, 2009. DOI: 10.1016/j.strusafe.2008.06.019.

[20] ISO 2394, General Principles on Reliability for Structures, ISO: Geneva, Switzerland, 111 pp., 2015.

[21] ASCE 7-10, Minimum Design Loads for Buildings and Other Structures, American Society of Civil Engineers: Reston, VA, 593 pp., 2013.

[22] Lee, K., Cho, H. \& Cha, C., Life-cycle cost-effective optimum design of steel bridges considering environmental stressors. Engineering Structures, 28(9), pp. 1252-1265, 2006. DOI: 10.1016/j.engstruct.2005.12.008.

[23] Ang, A.H.S. \& De Leon, D., Determination of optimal target reliabilities for design and upgrading of structures. Structural Safety, 19(1), pp. 91-103, 1997. DOI: 10.1016/S0167-4730(96)00029-X.

[24] Ang, A. \& De Leon, D., Modeling and analysis of uncertainties for risk-informed decisions in infrastructures engineering. Structure and Infrastructure Engineering, 1(1), pp. 19-31, 2005. DOI: 10.1080/15732470412331289350.

[25] Ghasemi, S.H. \& Nowak, A.S., Target reliability for bridges with consideration of ultimate limit state. Engineering Structures, 152, pp. 226-237, 2017. DOI: https://doi.org/10.1016/j.engstruct.2017.09.012.

[26] Vrouwenvelder, A.C.W.M., Target reliability as a function of the design working life. Proceedings of the 6th IFED Forum, 2012.

[27] Sykora, M., Holicky, M. \& Markova, J., Verification of existing reinforced concrete bridges using the semi-probabilistic approach. Engineering Structures, 56, pp. 14191426, 2013. DOI: http://dx.doi.org/10.1016/j.engstruct.2013.07.015.

[28] Caspeele, R., Sykora, M., Allaix, D.L. \& Steenbergen, R., The design value method and adjusted partial factor approach for existing structures. Structural Engineering International, 23(4), pp. 386-393, 2013. DOI: 10.2749/101686613X13627347 100194.

[29] Zwicky, D., SIA 269/2 - A new Swiss code for the conservation of concrete structures. Proceedings of the 3rd fib International Congress, Precast/Prestressed Concrete Institute: Chicago, 13 pp., 2010.

[30] Vrouwenvelder, A.C.W.M. \& Scholten, N., Assessment criteria for existing structures. Structural Engineering International, 20(1), pp. 62-65, 2010.

[31] Steenbergen, R.D.J.M., Sykora, M., Diamantidis, D., Holicky, M. \& Vrouwenvelder, A.C.W.M., Economic and human safety reliability levels for existing structures. Structural Concrete, 16, pp. 323-332, 2015. DOI: 10.1002/suco.201500022.

[32] Diamantidis, D. \& Sykora, M., Optimizing monitoring - implementation of draft guideline and case study of roof exposed to snow loads (under review). Proceedings of the 40th IABSE Symposium, 8 pp., 2018.

[33] Holický, M., Tanner, P., Steenbergen, R., Nuti, C., Shave, J. \& Schnell, J., Assessment of Existing Structures (Final Draft of the Technical Specification, Oct. 2017), CEN TC250/WG2.T1, 37 pp., 2017. 